\title{
Cardiovascular risk factors of poor prognosis in COVID-19 - a review
}

\section{Eli A. Zaher}

Center for Medical Education in English, Poznan University of Medical Sciences, Poland

(iD) https://orcid.org/0000-0003-1476-2009

\section{Daria M. Keller}

Ist Department of Cardiology, Poznan University of Medical Sciences, Poland

Corresponding author: daria.keller@skpp.edu.pl

(iD) https://orcid.org/0000-0002-8570-1812

\section{Nanthushan Suntharampillai}

Center for Medical Education in English, Poznan University of Medical Sciences, Poland

(iD) https://orcid.org/0000-0002-9523-6926

Endrit Ujkani

Sørlandet Sykehus HF, Kristiansand, Norway

(iD) https://orcid.org/0000-0003-0272-1808

\section{Maciej Lesiak}

Ist Department of Cardiology, Poznan

University of Medical Sciences, Poland

(D) https://orcid.org/0000-0003-2630-5016
이 DOI: https://doi.org/10.20883/medical.e571

Keywords: COVID-19, SARS-CoV-2, cardiovascular system, risk factors, poor prognosis

Published: 2021-12-29

How to Cite: Zaher EA, Keller DM, Suntharampillai N, Ujkani E, Lesiak M. Cardiovascular risk factors of poor prognosis in COVID-19 - a review. Journal of Medical Science. 2021 Dec 29;90(4):e571. doi:10.20883/medical.e571.

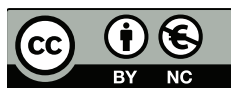

(c) 2021 by the author(s). This is an open access article distributed under the terms and conditions of the Creative Commons Attribution (CC BY-NC) licencse. Published by Poznan University of Medical Sciences

\begin{abstract}
Since the first report in 2019, COVID-19 has claimed many lives, even those previously in good health. Therefore, a proper diagnosis and identification of patients at the highest risk of serious complications is vital. In fact, COVID-19 can lead to systemic inflammation and multiorgan dysfunction. Apart from the respiratory system, the circulatory system is also affected, including numerous complications due to the cytokine storm, direct cytotoxic effects, downregulation of angiotensin-converting enzyme 2, and low oxygen blood levels. In this review, we discussed cardiovascular risk factors associated with a poor prognosis in COVID-19 patients, including pre-existing risk factors or those acquired in the course of the infection. We also analyzed the role of biomarkers, ECG, and imaging in the identification of patients at the highest risk of unfavorable outcomes, as even subtle abnormalities in additional tests may have a significant impact on disease management.
\end{abstract}

\section{Introduction}

Coronavirus disease 2019 (COVID-19) is caused by severe acute respiratory syndrome coronavirus 2 (SARS-CoV-2). It was first reported in Wuhan, China, in December 2019 and quickly escalated into a global pandemic declared by the World Health Organization on March 11 $1{ }^{\text {th }}, 2020$.
SARS-CoV-2 and the cardiovascular system SARS-CoV-2 is an enveloped, positive-sense single-stranded RNA virus (+ssRNA) from the Betacoronavirus genus which includes severe acute respiratory syndrome coronavirus (SARS-CoV) and Middle East respiratory syndrome coronavirus (MERS-CoV), i.e. diseases with their own pan- 
demics. In fact, SARS-CoV-2 was shown to share many similarities with SARS-CoV, including their mode of entry and nearly $80 \%$ of the genomic sequence.

In order to gain entry into human cells, the virus uses a spike protein to bind to a cellular receptor angiotensin-converting enzyme 2 (ACE2). This receptor is found in various organs, such as the lungs, heart, kidneys, and intestines $[1,2]$, and this fact could account for the association of SARS-CoV-2 with cardiovascular (CV) complications [3].

ACE2 degrades the product of ACE, angiotensin II, and converts it into angiotensin 1-7, which has anti-hypertrophic, anti-fibrotic, vasodilatory, and anti-hypoxic effects on the heart. Thus, ACE2 acts as a counterbalance to the renin-angiotensin-aldosterone system, and participates in cardioprotection [4].

In addition to the respiratory and CV manifestations, SARS-CoV-2 can trigger thromboembolic events and a cytokine storm [3]. Cytokine storm refers to the uncontrolled immune cell activation and overproduction of pro-inflammatory cytokines. Furthermore, it increases the levels of reactive oxygen species and causes endothelial cell dysfunction, disruption of blood supply, and multiple organ failure [5]. This, in turn, could further enhance the spreading of SARS-CoV-2, as ACE2 was found to be an interferon-stimulated gene [1].

Therefore, the CV system could be affected in a number of ways, potentially in synergy through (a) direct myocardial injury resulting from viral binding to ACE2 and the subsequent downregulation of ACE2 expression, (b) systemic inflammation resulting in the organ failure, increase in the myocardial demand-supply ratio, atherosclerotic plaque rupture, as well as electrolyte imbalance, (c) decreased blood oxygen levels as a result of pulmonary damage, and (d) COVID-19 therapies which negatively affect the CV system - including antiretroviral therapy, azithromycin and tocilizumab $[3,5]$. The impact of SARS-CoV-2 on the CV system is presented in Figure 1.

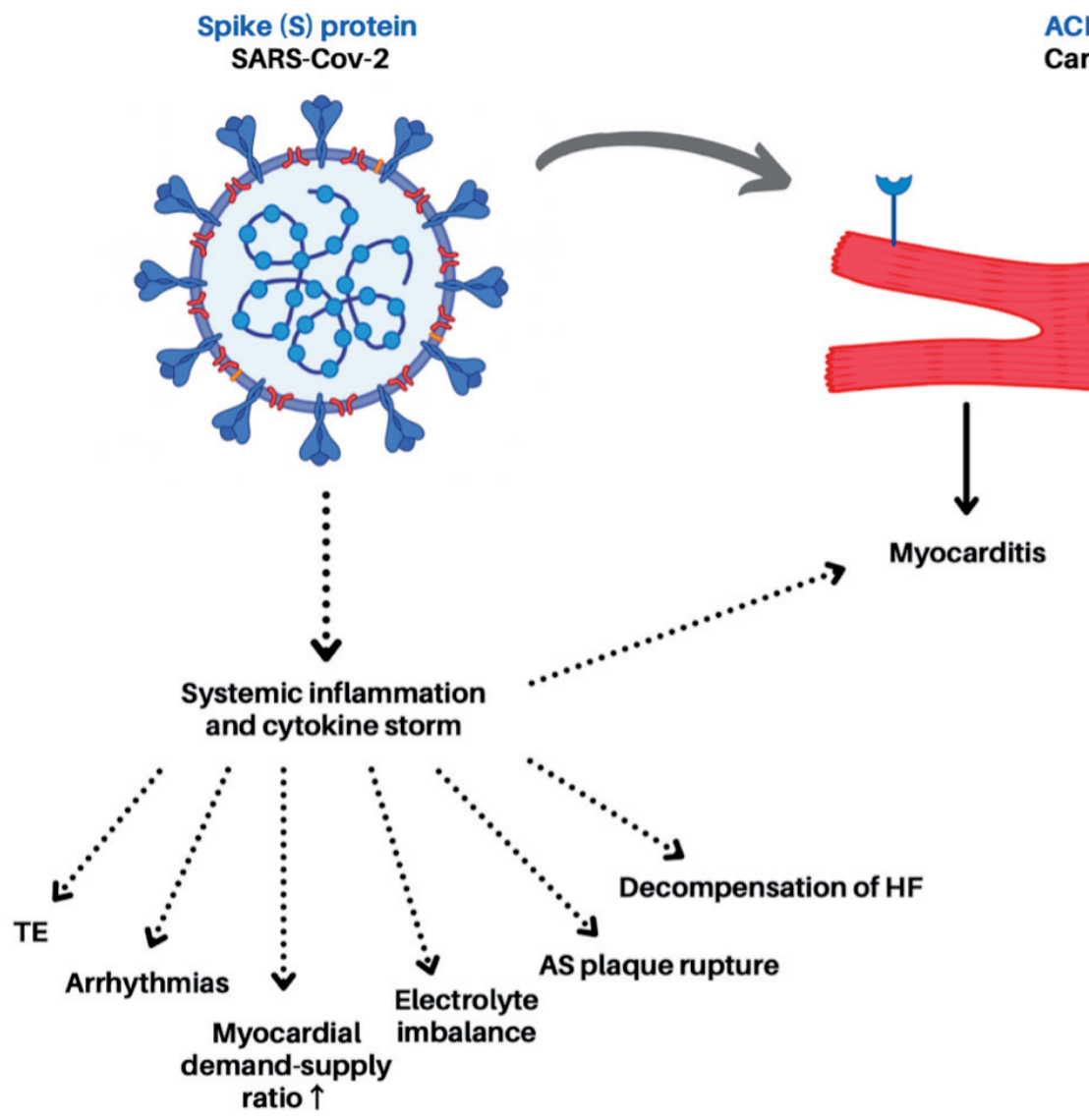

Figure 1. The impact of SARS-CoV-2 on the cardiovascular system. ACE2 - angiotensin-converting enzyme 2, AS - atherosclerosis, $\mathrm{HF}$ - heart failure, RAAS - renin-angiotensin-aldosterone-system, TE - thromboembolism 
Due to the tropism of SARS-CoV-2 towards the heart and its ability to exacerbate, or even cause CV disease, it is vital to monitor the hearts of patients suffering from COVID-19, particularly those with CV comorbidities, since they are more likely to develop severe presentations of COVID-19. Moreover, diabetes, hypertension, and cerebrovascular diseases were also associated with a higher risk of severe COVID-19 presentations [2]. The aforementioned non-communicable diseases, in addition to cancer and chronic respiratory disease, constitute a syndemic with COVID-19 posing a significant strain on our healthcare systems and increasing the risk of premature death [6].

The link between the treatment with angiotensin-converting enzyme inhibitors, or angiotensin II receptor blockers, and the upregulation of ACE2 expression is controversial, with studies showing inconsistent and mixed results [7-11]. Angiotensin-converting enzyme inhibitors and angiotensin II receptor blockers do not have a direct effect on ACE2, and there is no evidence of COVID-19 susceptibility stemming from ACE2 upregulation. Therefore, several medical societies have recommended the continuation of treatment with those drugs [2].

\section{Factors of poor prognosis in COVID-19}

\section{Cardiovascular complications}

CV complications of COVID-19 include myocardial injury, myocarditis, acute myocardial infarction (AMI), heart failure (HF), arrhythmias, and venous thromboembolic events [12].

COVID-19 may disproportionately affect individuals suffering from $\mathrm{CV}$ diseases, in particular patients with coronary artery disease (CAD) and HF. A meta-analysis which analyzed 22,148 patients from 40 studies showed that the underlying CV disease in COVID-19 patients was correlated with a poorer prognosis, including a more severe course of COVID-19, intensive care unit (ICU) admissions, and disease progression [13].

\section{Myocarditis}

Myocarditis constitutes a potentially serious cardiac complication of COVID-19. It refers to the inflammation of the myocardium characterized by inflammatory infiltrates and myocardial injury without an ischemic cause. Direct viral injury and further cardiac damage due to the body's immune response to the virus are believed to be the pathophysiologic causes underlying COVID-19related myocarditis. Although it is not an uncommon complication, the true incidence of myocarditis in COVID-19 patients remains unknown. This is due to its highly variable clinical presentation, lack of reliable laboratory tests, and non-sensitive or specific findings on ECG. In fact, patients usually require further testing in order to establish a diagnosis of myocarditis using either echocardiography, cardiac magnetic resonance imaging (CMR), or endomyocardial biopsy [14, 15].

Symptoms of COVID-19-related myocarditis are most commonly mild [15]. However, if myocardial dysfunction develops, the prognosis becomes poor [16]. Patients with comorbid cardiac diseases and those with concomitant elevated troponins tend to present worse outcomes [15]. The management is focused on supportive care with fluids, remdesivir, and close monitoring. Additionally, patients who develop cardiogenic shock (CS) will require inotropes, mechanical ventilation, and possibly temporary mechanical circulatory support $[14,15]$.

\section{Ischemic heart disease}

\section{Patients without prior cardiovascular disease}

Several articles reported evidence of AMI type 2 , or myocardial infarction with non-obstructive coronary arteries among patients with COVID-19. The former is explained by the presence of high levels of ACE2 receptors in pericytes and in endothelial cells, which inhibits a severe microvascular dysfunction also associated with cytokine storm [17].

\section{Acute myocardial infarction}

Although in certain areas a decrease of up to $50 \%$ in AMI cases was reported during the COVID-19 pandemic [18, 19], AMI has been recognized as a severe cardiac complication in COVID19 patients, and can also develop in individuals without prior $\mathrm{CV}$ conditions. This is possibly accounted for by the extensive inflammation and hypercoagulability resulting from the disease. Furthermore, a direct viral injury of myocardial cells and oxygen imbalance caused by pneumonia are additional potential contributors [20, 21]. 
One study suggested investigating inflammatory markers and $\mathrm{N}$-terminal pro-B type natriuretic peptide (NT-proBNP) in COVID-19 patients with concomitant $\mathrm{AMI}$, as these were shown to be elevated and can be effective in determining the disease severity. The same study demonstrated higher mortality from COVID-19 in patients experiencing AMI compared to those without AMI [22]. Even after undergoing percutaneous coronary intervention for STEMI - in-hospital mortality, stent thrombosis, and CS remain significantly higher in COVID-19 patients [23].

\section{Myocardial infarction with nonobstructive coronary arteries}

Myocardial infarction with nonobstructive coronary arteries is clinically defined in patients who fulfil the universal AMI criteria, yet have less than $50 \%$ stenosis in coronary angiography [24]. One study investigated patients with both obstructive and nonobstructive coronary arteries who suffered AMI in the course of an underlying COVID-19 infection. Both their in-hospital mortalities were high, and no difference was found between the two groups of patients [25].

\section{Patients with prior coronary artery disease}

According to the findings of Zhou et al., CAD is a risk factor of increased mortality in the course of COVID-19 [26]. However, a study conducted in Italy on 1,252 COVID-19 patients demonstrated that age and female gender were the only independent correlates of mortality (where age was a risk factor and female gender was a protective factor). Patients with $C A D$ presented a poorer prognosis, although this was mainly attributed to older age and a higher rate of comorbidities rather than to a direct consequence of CAD [27]. In another study from Italy, COVID-19 patients who underwent high-resolution computed tomography (CT) were retrospectively evaluated by the coronary calcium score (CCS). Only patients with subclinical CAD were included in the study, and out of 53 patients analyzed, $50 \%$ of individuals with CCS $\geq 400$ had died, compared to only $8.9 \%$ of patients with a CCS $<400$. The independent predictive role of CCS could not be ultimately determined due to a very small study group. However, a high CCS score can be a marker of worse in-hospital outcomes, although it may also indicate an increased baseline risk. Never- theless, including a CCS assessment in a routine high-resolution CT evaluation in COVID-19 patients can deliver useful prognostic information without additional costs [28].

\section{Heart failure}

Patients with congestive HF have a significantly poorer prognosis in the course of COVID-19. In fact, certain cases have been observed where COVID-19 has caused a decompensation of underlying HF, leading to CS [29]. A retrospective case series conducted in Wuhan, China, further consolidates the importance of early cardiac monitoring in patients with congestive $\mathrm{HF}$, due to the high correlation between the disease and mortality [30]. However, acute HF also occurred in patients without underlying $\mathrm{HF}$, leading to a significantly higher mortality $(46.8 \%$ vs. $19.7 \%$; $\mathrm{p}<0.001)$ [31].

\section{Arrhythmias}

Arrhythmias are not uncommon in viral infections and were also demonstrated in COVID-19 patients. The most probable causes comprise such elements as fever, stress, hypoxia, electrolyte imbalances, and usage of antiviral drugs. In Wuhan, China, over $44 \%$ of ICU COVID-19 patients presented arrhythmias. Furthermore, sinus bradycardia is one of the most common arrhythmias seen in COVID-19 patients and it can persist for up to 2 weeks [32]. A case study following two patients with COVID-19 related bradycardia demonstrated a positive response to epinephrine, deeming temporary pacing unnecessary [33]. Interestingly, atrial fibrillation is also widely reported. The treatment is focused on rhythm control and anticoagulation simultaneously avoiding non-pharmacological interventions. Thus, catheter ablation and electrical cardioversion should be avoided, if possible, during an active infection [34]. Other atrial and ventricular arrhythmias, including ventricular fibrillation, were also reported in patients who showed no previous evidence of arrhythmia and were not on QT-prolonging medications. It is also essential to monitor COVID-19 patients with continuous telemetry, as the development of new-onset arrhythmia is associated with a severe course of the disease [32].

In addition, some patients suffering from inherited arrhythmias, such as long-QT syn- 
drome, Brugada syndrome, short-QT syndrome, and catecholaminergic polymorphic ventricular tachycardia, may be at a higher risk of developing arrhythmias following SARS-CoV-2 infection [35].

Chloroquine, a medication primarily used to prevent and treat malaria, was administered to COVID-19 patients early in the pandemic, as it interferes with the terminal glycosylation of ACE2, which may disturb virus-receptor binding and thus prevent infection. The use of chloroquine and its derivative hydroxychloroquine was halted in summer 2020 due to the lack of a benefit seen in the randomized clinical trials and the potential for toxicity. Although chloroquine and hydroxychloroquine have QT-prolonging effects, they are mostly modest and do not require special attention in the long-QT syndrome. However, since they are metabolized by CYP3A4, these substances should be used with caution when in combination with other antiviral medications inhibiting CYP3A4, such as ritonavir-lopinavir, azithromycin, or remdesivir [35].

It is generally accepted that sodium channel function is sensitive to temperature. Fever stemming from COVID-19 can thus disturb the mutant sodium channels in Brugada syndrome and trigger arrhythmias. In fact, the presence of a pathogenic variant in SCN5A was shown to be of particular importance for Brugada syndrome patients who develop life-threatening arrhythmic events in the setting of fever. Hence, it is vital for Brugada syndrome patients to receive antipyretics immediately if they develop a fever [35].

In terms of the short-QT syndrome, it is extremely rare without any specific triggers for life-threatening arrhythmic events. Therefore, patients experiencing it are not expected to be at risk when infected with SARS-CoV-2 [35].

It is worth bearing in mind that exercise and stress are specific triggers for life-threatening arrhythmic events in catecholaminergic polymorphic ventricular tachycardia. Fever, however, is not. Hence, the risk of COVID-19 arrhythmias in those patients is controversial. It is important to avoid drugs with alpha- or beta-adrenoceptor mimetic activity, such as epinephrine during hemodynamic support, due to their ability to unmask ventricular arrhythmias in catecholaminergic polymorphic ventricular tachycardia patients [35].

\section{Thrombotic complications}

The mechanisms of increased thrombotic complications in COVID-19 patients are not exactly understood. However, any of the three factors in Virchow's triad may contribute to thrombosis. COVID-19 can result in hypoxia, leading to increased blood viscosity, and abnormal blood flow. Additionally, SARS-CoV-2 also causes a state of increased inflammation, resulting in a hypercoagulable state due to a release of inflammatory cytokines [30]. As the virus enters cells through the ACE2 receptor, also found in the endothelial cells, it triggers the production of mitochondrial reactive oxygen species, glycolytic shift, and endothelial damage. In fact, spike protein alone can damage endothelium by downregulating ACE2 and as a consequence inhibiting mitochondrial function [36].

Among different negative prognostic factors, a high D-dimer score on admission has been reported to be a significant risk factor for severe disease course and mortality [36].

A retrospective cohort study from China demonstrated that D-dimer levels above $1 \mu \mathrm{g} / \mathrm{mL}$ increased the chance of in-hospital death [26]. Another study from Wuhan further consolidated this statement indicating that a high D-dimer, high fibrin degradation products, longer prothrombin time, and activated partial thromboplastin time during admission were common in patients who died [37].

In addition, another study revealed that, although not helpful to all patients, heparin administration decreased the 28-day mortality in patients with a sepsis-induced coagulopathy score $\geq 4$, or D-dimer $>6$-fold of the upper limit of normal [38].

D-dimer levels can be used to exclude a pulmonary embolism (PE) in case of a normal value, but it is not recommended as a positive marker, due to low specificity. Bompard et al. suggest using contrast-enhanced CT to exclude PE, if supplementary oxygen is required in infected patients [39].

$\mathrm{PE}$, as well as thrombotic complications in general, constitute greater threats and are tremendously more common in the ICU patients than in the non-ICU patients. A study conducted in the Netherlands enrolled 184 patients with proven COVID-19 pneumonia that were admitted to the ICU. 23 of them died, 22 were discharged home, 
and 139 were still in the ICU by the end of the study. Despite receiving at least standard-dose thromboprophylaxis, $31 \%(95 \% \mathrm{Cl} 20-41)$ of patients suffered thrombotic complications, with PE being the most common one $(n=25.81 \%)$. The independent predictors of thrombotic complications were spontaneous prolongation of the prothrombin time (>3 s) and activated partial thromboplastin time (>5 s). These findings emphasize the importance of high-dose prophylactic anticoagulation in all ICU patients suffering from COVID-19 [40].

\section{Biomarkers}

Multiple studies hypothesized that measurement of cardiac damage biomarkers immediately after hospital admission for SARS-CoV-2 infection, followed by longitudinal monitoring during hospitalization, could help clinicians identify a subset of patients with a possible cardiac injury and predict the progression of COVID-19 towards a poorer outcome [41].

The prognostic value of cardiac biomarkers has been widely used in the management of CAD and HF. Troponins, B-type natriuretic peptide (BNP), and NT-proBNP are most commonly employed for the diagnosis, prevention, and safe discharge planning. Troponin is a marker of direct myocyte damage and necrosis, whereas BNP and NT-pro BNP are rather defined as markers for myocardial stretch injury. They can be also used in terms of the diagnosis, prevention, and safe discharge planning for patients hospitalized with CV diseases [42].

Troponin I (Tnl) constitutes a "gold standard" biomarker of necrosis used for the cardiac risk assessment. It is released exclusively in the cardiac muscle in the presence of myocardial injury irrespective of its mechanism [43]. Interesting$l y$, even in the absence of acute coronary syndrome (ACS), troponin elevation was identified in $20-30 \%$ of hospitalized patients with COVID19 and has been associated with an increased risk of mortality in retrospective studies $[44,45]$. A study from Zhou et al. on 191 patients, of whom 54 deceased due to COVID-19, revealed increased troponin I in over half of those who died. 91 (48\%) of the patients had comorbidities, such as hypertension (most common), diabetes mellitus, and CAD [26]. A cohort study by Shi et al., including 416 hospitalized COVID-19 patients, reported that approximately $20 \%$ of the subjects had evidence of a cardiac injury manifested by a significantly elevated high sensitivity troponin I (hs-Tnl). This finding, in turn, was associated with a higher in-hospital mortality ( $51.2 \%$ vs. $4.5 \%$ respectively; $p<0.001)[43,44]$. Similarly, a cohort study by Salvatici et al. on 523 patients with COVID-19 reported a $18.3 \%$ mortality during hospitalization, and significantly higher hs-Tnl levels in the deceased patients in comparison to the survivors (36.05 ng/L IQR $16.5-94.9$ vs. $6.3 \mathrm{ng} / \mathrm{L}$ IQR $2.6-$ 13.9; $p<0.001$ respectively) [46].

Furthermore, Singh et al. conducted a single-centered, retrospective, observational study on 276 patients who presented to the emergency department. In 261 (95\%) patients high sensitivity troponin $\mathrm{T}$ (hs-TnT) values were noted at presentation. The median initial hs-TnT value was $17 \mathrm{ng} / \mathrm{L}$. In fact, initial hs-TnT levels above median were associated with longer hospitalization, increased need for vasoactive agents, higher mortality, along with the composite end-point (in-hospital death, cardiac arrest, intubation, or need for critical care); (OR 3.92, $\mathrm{p}<0.001)$. From this patient group, only one $(<1 \%)$ with elevated hs-TnT had clinical evidence of ACS and underwent percutaneous coronary intervention. This finding supports the observation of Tersalvi et al. according to which elevated troponin levels are most likely the manifestation of an inflammatory response rather than true MI [41].

In addition to troponins, creatine kinase-MB (CK-MB) may also hold prognostic value in COVID-19 patients. It is an intracellular enzyme present in the skeletal muscle, myocardium, and brain. In the study conducted by Wang et al., 36 out of 138 patients $(26.1 \%)$ were admitted to the ICU. All the patients had significantly elevated TnI and CK-MB levels compared to the non-ICU patients, which indicates that myocardial injury is more severe in cases with a serious course of COVID-19 [47].

Myoglobin is a cytoplasmic protein which exists in the cardiac and skeletal muscle. It increases rapidly and is among the initial markers to be elevated. In the study by Yang et al., the levels of myoglobin in the critically ill COVID-19 patients were significantly higher than in the mildly affected patients. In a cross-sectional study by Yu et al. on 162 patients requiring ICU, myoglobin was elevated in 57 (35.2\%) patients. 
Even though myoglobin is not as cardiac-specific as troponins, it was positively correlated with CK-MB and troponin T $[47,48]$.

A multicenter observational study was conducted at Sichuan province and Wuhan city to establish the predictive value of biomarkers on 357 patients with confirmed COVID-19 infection from January to March, including 22 tertiary hospitals designated for COVID-19 patients in the area. After a 28-day follow up, patients were classified into survival $(n=332)$ or death groups $(n=25)$, and recovery $(n=314)$ or non-recovery $(n=43)$ groups. Myoglobin, CK-MB, and hs-TnT were significantly elevated in death and non-recovery groups. Least absolute shrinkage and selection operator regression (a machine learning regression which chooses the independent risk factors affecting outcomes and presents only the strongest predictors in the predictive model) was employed by Yang et al. in order to identify the strongest predictive biomarkers. The area under the curve (AUC) of myoglobin and CK-MB for in-hospital death were $0.838(95 \% \mathrm{Cl}$ : $0.729-$ $0.947, p<0.001)$ and $0.862(95 \% \mathrm{Cl}: 0.804-0.920$, $p<0.001$ ), respectively. The AUC of myoglobin and $\mathrm{CK}-\mathrm{MB}$ for non-recovery were $0.841(95 \% \mathrm{Cl}$ : $0.765-0.918, p<0.001)$ and 0.839 (95\%Cl: $0.786-$ $0.892, p<0.001$ ), respectively. Myoglobin and $\mathrm{CK}-\mathrm{MB}$ were considered as possible adverse prognosis predictors regarding in-hospital death and non-recovery in 28 days. In contrast, the method did not demonstrate the predictive value of hs-TnT in this study, whereas a combined use of CK-MB and myoglobin showed better predictive performance in terms of the prognosis $[47,48]$.

NT-proBNP is secreted in response to increased myocardial wall stress. Previous studies suggested that NT-proBNP could be a powerful predictor of mortality in community-acquired pneumonia The elevated NT-proBNP levels are claimed to be the result of cardiac complications following complex interactions among pre-existing conditions, relative ischemia, up-regulation of the sympathetic system, systemic inflammation, and direct pathogen mediated damage to the $\mathrm{CV}$ system $[49,50]$. A study by Gao et al. revealed that NT-proBNP correlated independently with in-hospital death of COVID-19 patients. The cut-off value of NT-proBNP to predict the fatal outcome of the disease was $>88.64 \mathrm{pg} / \mathrm{ml}$, and was significantly decreased as compared to the threshold used to diagnose $\mathrm{HF}(450 \mathrm{pg} / \mathrm{mL}$ for $<50$ years old, $900 \mathrm{pg} / \mathrm{mL}$ for $50-75$ years old and $1800 \mathrm{pg} / \mathrm{mL}$ for $>75$ years old) [49].

Lactate dehydrogenase (LHD) is an intracellular enzyme found in most cells. Although LHD can be used as a marker for cardiac damage, abnormal values can also be seen with multiple organ injuries. Henry et al. showed that elevated lactate dehydrogenase values in 1532 COVID-19 patients were associated with $a>6$-fold increase in odds of severe course of disease. Moreover, a $>16$-fold increase in the odds of mortality was also observed. Elevated levels of LHD measured at the earliest time point during the hospitalization were found in $>95 \%$ deceased patients and $<60 \%$ of survivors. Therefore, since elevated LHD levels reflect multiple organ injuries, they may play a prominent role in the triage of patients with COVID-19 [51, 52].

It is also of importance to note that in terms of the massive proinflammatory and prothrombotic cytokine storm associated with COVID-19 infection, not only cardiac biomarkers are increased, but also many others, e.g. IL-6, CRP, ferritin and D-dimers $[26,53,54]$

\section{ECG}

ECG is a widely available tool which monitors the electrical activity of the heart and is often used to aid the diagnosis and stratify the risk in heart diseases. A study which continuously monitored the ECGs of 159 COVID-19 patients on admission for 7 days, found a significant correlation between abnormal ECG and major adverse events. $49.1 \%$ of patients had abnormal ECG findings on admission, and $53.5 \%$ at day 7 . Ischemic changes and left ventricular hypertrophy correlated with a higher risk of major adverse events. The multivariable analysis demonstrated that abnormal ECG on the $7^{\text {th }}$ day of hospitalization was an independent predictor of major adverse events (HR 3.2, 95\% Cl 1.2-8.7; $p=0.02$ ). In addition, patients with irregular ECGs at day 7 were more likely to need renal replacement therapy and an ICU admission. The study also found that a high heart rate and its increase at day 7 could point to a strong systemic inflammatory reaction, whereas low QRS voltages could indicate significant lung damage, and the widening of QRS complex at the time of hospital stay could be significant of direct myocardial injury [55]. 
Another study followed the ECGs of 50 patients with COVID-19 pneumonia. On admission, 63\% experienced either left ventricular hypertrophy or ST-T abnormalities. Another 26\% developed new ECG irregularities, with changes indicating acute pericarditis being the most prevalent (12\%). This may be due to the expression of ACE2 receptors in epicardial adipocytes, which were associated with atrial electrical remodeling and progression to atrial fibrillation. This suggests that involving the epicardial adipocytes in COVID-19 patients (for instance, by developing pericardial effusion) may increase the risk of developing atrial fibrillation [56]. Possible ECG abnormalities in the course of COVID-19 infection are presented in Figure 2. in echocardiography, simplified protocols are preferred to reduce exposure, while advanced analysis can be performed in post-processing [57].

Echocardiographic examination in patients with COVID-19 allows for a hemodynamic evaluation, as well as for the identification of typical features of myocarditis, HF, ACS, or PE [58]. According to Cresti et al., left ventricular dysfunction, fortunately often reversible, is common even among patients without prior CV disease [57]. In a prospective international survey by Dweck et al., 55\% of patients with suspected or confirmed COVID-19 ( $n=1.216)$ demonstrated an abnormal echocardiogram (including 46\% without pre-existing heart disease; $n=901$ ) [59]. In another study, $26 \%$ of COVID-19 patients $(n=125)$ showed left ven-

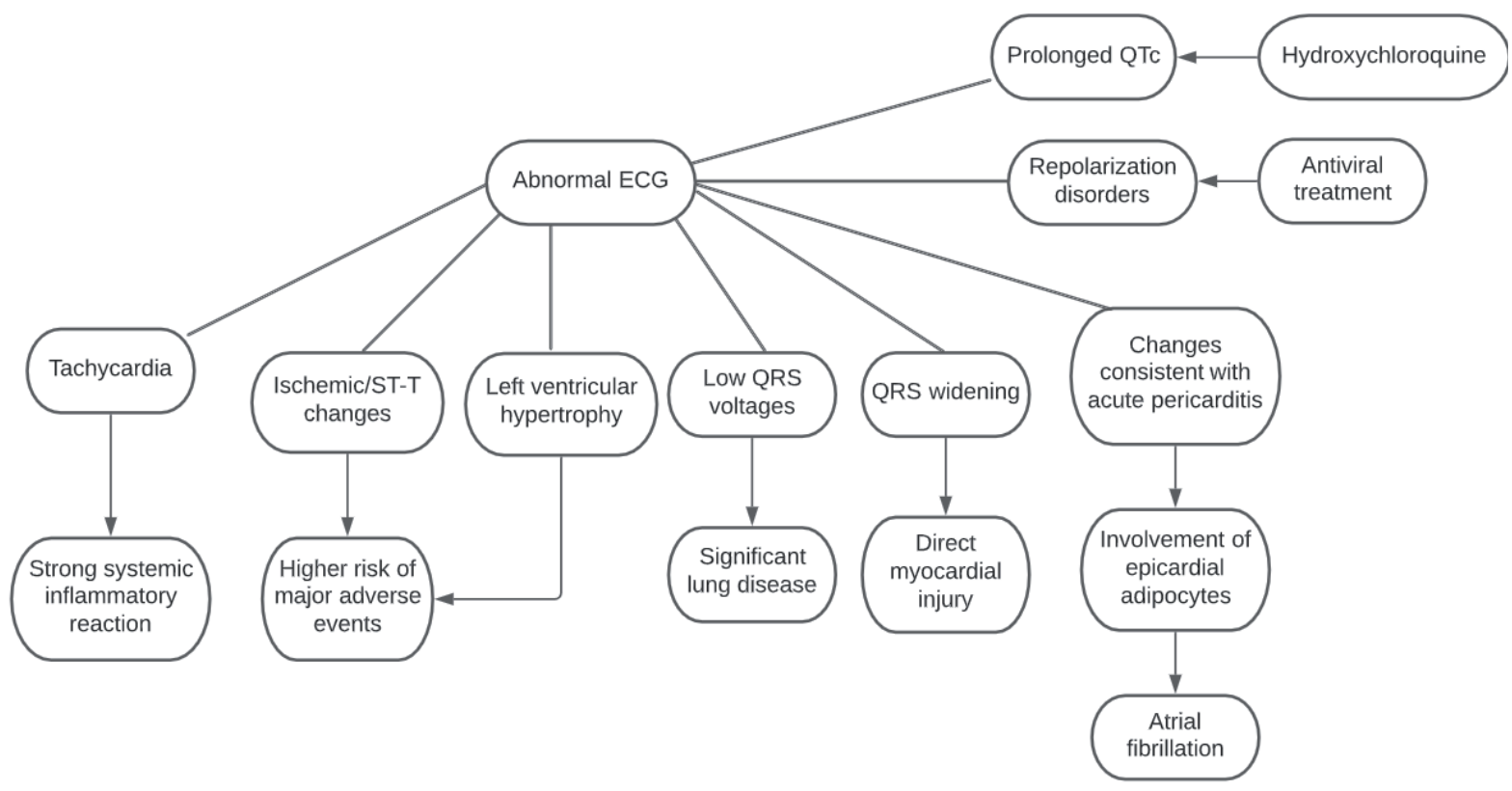

Figure 2. ECG changes in COVID-19 [on the basis of 55, 56]

\section{Cardiovascular imaging}

As cardiac involvement in COVID-19 is common and leads to an increased mortality, imaging techniques play a pivotal role in the differential diagnosis and risk stratification of CV manifestations [5]. Bedside ultrasound assessment of the heart and vessels is an effective first-line tool in detecting any abnormalities, whereas advanced techniques may facilitate final diagnosis and decision-making. In fact, echocardiography is frequently used in the initial assessment of acute myocardial injury. However, both logistic and sanitizing problems limit the use of CMR and CT. Even tricular impairment, defined as a left ventricular ejection fraction $<50 \%$, or segmental wall motion abnormalities [60]. However, it is postulated that it is the right ventricular (RV) dysfunction predicts mortality in COVID-19 patients, which is frequently secondary to acute respiratory distress syndrome [57]. Li et al. performed echocardiographic examination in 120 COVID-19 patients and measured the conventional RV functional parameters including RV fractional area change, TAPSE (tricuspid annular plane systolic excursion), and tricuspid tissue Doppler annular velocity, as well as RVLS (right ventricular longitudinal strain) obtained by speck- 
le-tracking echocardiography. In fact, it has been recently demonstrated that RVLS is a more accurate tool to estimate RV function. It was found that non-survivors had enlarged right cardiac chambers, declined RV function, and elevated pulmonary artery systolic pressure compared to survivors. Additionally, RVLS, RV fractional area change, and TAPSE were significant univariate predictors of a higher mortality risk $(p<0.05)$. Patients in the lowest RVLS tertile, in comparison with those in the highest tertile, were more likely to have higher heart rates, as well as elevated D-dimer and CRP levels. They also required more high-flow oxygen and invasive therapy. The incidence of acute myocardial injury, acute respiratory distress syndrome, and deep-vein thrombosis was higher in the lowest tertile. Furthermore, the same association was observed in the case of mortality. The best cutoff value of RVLS for prediction of fatal outcomes was $-23 \%$ (AUC: $0.87 ; p<0.001$; sensitivity, $94.4 \%$; specificity, $64.7 \%)$. The abovementioned results support the application of RVLS in the risk stratification in COVID-19 patients [61].

CMR with its new quantitative mapping techniques is particularly effective in the diagnosis and risk stratification of acute myocardial injury in the course of COVID-19. A systematic review of 34 studies comprising CMRs in 199 patients revealed that only $21 \%$ of examinations were with the normal limits. The most prevalent diagnosis was myocarditis (40.2\%) (presented in Figure 3). Furthermore, T1 (109/50; 73\%) and T2 (91/144; $63 \%)$ mapping abnormalities, edema (46/90; $51 \%)$ and late gadolinium enhancement $(85 / 199 ; 43 \%)$ were the most common findings. Late gadolinium enhancement was most commonly seen in the subepicardial location (81\%) in inferior segments [62]. Interestingly, it was present in a lower proportion in COVID-19 subjects when compared to patients with myocarditis, yet without COVID-19. This supports the hypothesis that inflammation constitutes the primary mechanism of myocardial injury in SARS-CoV-2 infection [63].

CT allows for the evaluation of lung parenchyma, patency of coronary and pulmonary arteries, and the assessment of myocardial injury, which renders it a comprehensive, non-invasive imaging modality allowing "quadruple rule-out" of most serious $\mathrm{CV}$ complications in the course of COVID-19 infection [64]. Although CMR is more frequently used in myocarditis detection, imaging of myocardial fibrosis by CT is feasible. Specifically, late iodine enhancement CT and extracellular volume $\mathrm{CT}$ are able to identify focal fibrosis and diffuse myocardial injury, respectively [65]. Furthermore, CT coronary angiogram can replace invasive coronary angiography in excluding obstructive CAD for patients with thoracic pain in the course of infection. In addition, it also allows for the estimation of the already discussed CCS, which is an independent predictor of in-hospital mortality and ICU admission [21]. Finally, CT pulmonary angiography has a crucial role in the diagnostic evaluation of COVID-19 complicated with acute PE [64].

\section{Summary}

Patients suffering from COVID-19 are at risk of developing $\mathrm{CV}$ complications and require close monitoring, especially those with $\mathrm{CV}$ comorbidities.

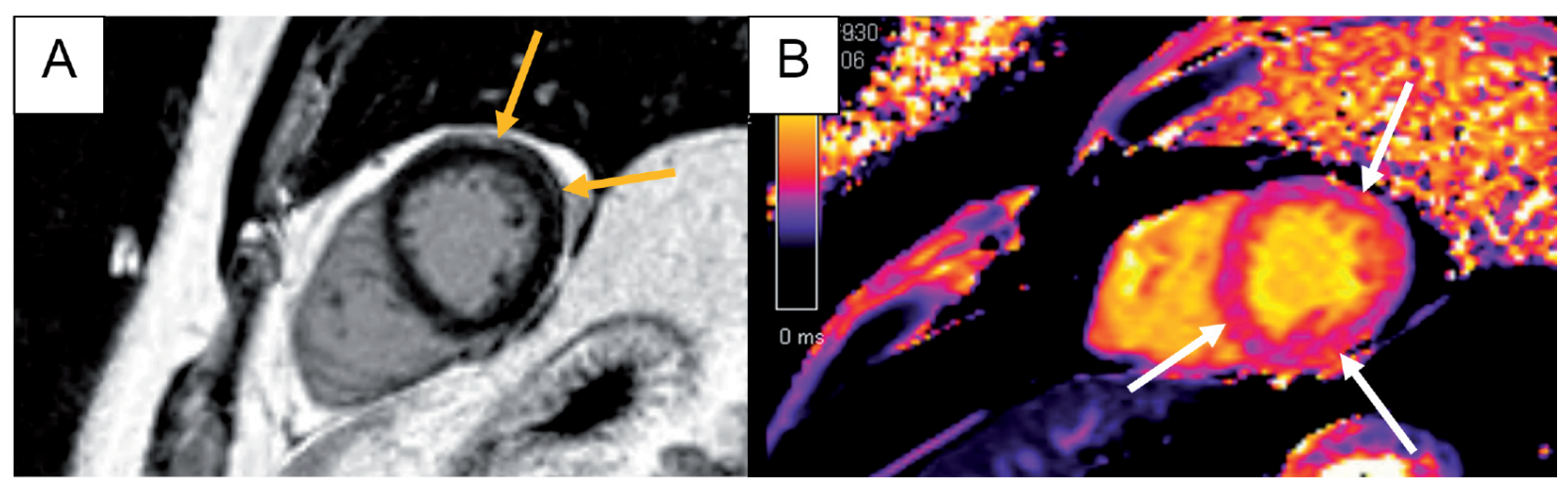

Figure 3. Myocardial injury on CMR 3 months after COVID-19: A: intramural fibrosis - late gadolinium enhancement in short axis view (arrows); B: diffuse fibrosis - T1 map in short axis view; native T1 in affected area $=1029 \mathrm{~ms}$ (normal values: $967 \pm 14 \mathrm{~ms}$ ) [with the courtesy of Prof. Małgorzata Pyda; Poznan University of Medical Sciences CMR Unit, Cath Lab] 
SARS-CoV-2 enters cardiomyocytes via their ACE2 receptor and interferes with its cardio-protective activity in the process. The systemic inflammation caused by COVID-19 further damages the heart by mis-balancing electrolyte levels and the myocardial demand-supply ratio. Decreased blood oxygen levels from pulmonary damage subsequently contribute to complications. As a result, the negative impact of SARS-CoV-2 on the cardiovascular system may manifest as myocardial injury, myocarditis, AMI, HF, arrhythmias, and venous thromboembolic events. In addition, some of the medications used to combat the disease, have a negative impact on the $\mathrm{CV}$ properties.

We analyzed numerous $\mathrm{CV}$ factors in order to identify those indicating an increased probability of a fatal outcome. As SARS-CoV-2 disproportionately affects people suffering from CV diseases, a prior $\mathrm{CV}$ disorder (especially hypertension, CAD and $\mathrm{HF}$ ) is the greatest risk factor of unfavorable prognosis. Similarly, the development of any serious CV complication in the course of COVID-19 decreases the chances of survival.

Fortunately, there are certain risk factors which can also contribute to an increased alertness in terms of the anticipated disturbing symptoms and better prevention. The use of the CCS in addition to the high-resolution $\mathrm{CT}$ deserves special attention, since it helps in identifying patients with CAD with a higher baseline risk of adverse outcomes without additional costs. Another example is high D-dimer levels, which are vital in the process of ruling out thrombotic events. Markedly worse outcomes of COVID-19 patients with thrombotic complications highlighted the importance of thrombosis prophylaxis in all subjects admitted to ICUs. Furthermore, as the development of new-onset arrhythmia is associated with a severe disease course, continuous telemetry constitutes another useful tool in COVID-19 management. In addition, extra caution should be taken in patients with inherited arrhythmic disorders due to their increased risk of developing life-threatening arrhythmic events. ECG abnormalities during hospitalization also correlate with a higher risk of major adverse events.

Cardiac biomarkers can be used to assess the severity of the SARS-CoV-2 impact on the $\mathrm{CV}$ system. The elevated levels of $\mathrm{Tnl}$ indicating myocardial necrosis have been associated with an increased risk of mortality, and have been observed even in patients without ACS Myoglobin and CK-MB have also been suggested as possible negative prognosis predictors regarding in-hospital death and non-recovery. Furthermore, NT-proBNP has been independently correlated with in-hospital death following adjustment for potential risk factors. In turn, the role of lactate dehydrogenase is uncertain, as elevated levels reflect multiple organ injuries. Nevertheless, it may play a prominent role in the triage of patients with COVID-19.

Overlapping clinical presentations and complex etiology of myocardial injury in COVID-19 require additional cardiac imaging to establish the diagnosis, guide therapy and stratify the risk of fatal outcome. Bedside ultrasound assessment of the heart and vessels is an effective first-line tool in detecting any abnormalities, although some patients may need advanced techniques. It is postulated that RV dysfunction predicts mortality in COVID-19 patients, and RVLS is a particularly accurate parameter. Furthermore, CMR is especially advantageous for the diagnosis of myocarditis. Finally, CT is efficient in the evaluation of lung parenchyma, patency of coronary and pulmonary arteries, and myocardial injury, making it the best non-invasive imaging modality allowing "quadruple rule-out" of the most serious CV complications.

We believe that the negative impact of SARS-CoV-2 not only on the respiratory, but also on the circulatory system, requires an integrated assessment of numerous $\mathrm{CV}$ risk factors of poor prognosis. Clinical evaluation of the possible CV complications, laboratory tests, ECG-monitoring, and $\mathrm{CV}$ imaging should be applied in order to provide the best possible management to COVID-19 patients, particularly those requiring hospitalization.

\section{Acknowledgements}

\section{Conflict of interest statement}

The authors declare no conflict of interest.

\section{Funding sources}

There are no sources of funding to declare.

\section{References}

1. Asselah T, Durantel D, Pasmant E, Lau G, Schinazi RF. COVID-19: Discovery, diagnostics and drug development. J Hepatol. 2021 Jan;74(1):168-184. doi: 
10.1016/j.jhep.2020.09.031. Epub 2020 Oct 8. PMID: 33038433.

2. Nishiga $M$, Wang DW, Han $Y$, Lewis DB, Wu JC. COVID-19 and cardiovascular disease: from basic mechanisms to clinical perspectives. Nat Rev Cardiol. 2020 Sep;17(9):543-558. doi: 10.1038/s41569-020-0413-9. Epub 2020 Jul 20. PMID: 32690910.

3. Bansal M. Cardiovascular disease and COVID-19. Diabetes Metab Syndr. 2020 May-Jun;14(3):247-250. doi: 10.1016/j.dsx.2020.03.013. Epub 2020 Mar 25. PMID: 32247212.

4. Patel VB, Zhong JC, Grant MB, Oudit GY. Role of the ACE2/Angiotensin 1-7 Axis of the Renin-Angiotensin System in Heart Failure. Circ Res. 2016 Apr 15;118(8):1313-26. doi: 10.1161/ CIRCRESAHA.116.307708. PMID: 27081112.

5. Catapano F, Marchitelli L, Cundari G, Cilia F, Mancuso G, Pambianchi G, Galea N, Ricci P, Catalano C, Francone M. Role of advanced imaging in COVID-19 cardiovascular complications. Insights Imaging. 2021 Feb 24;12(1):28. doi: 10.1186/s13244-021-00973-z. PMID: 33625637.

6. Di Ciaula A, Krawczyk M, Filipiak KJ, Geier A, Bonfrate L, Portincasa P. Noncommunicable diseases, climate change and iniquities: What COVID-19 has taught us about syndemic. Eur J Clin Invest. 2021 Sep 22:e13682. doi: 10.1111/eci.13682. Epub ahead of print. PMID: 34551123.

7. Vaduganathan $M$, Vardeny $O$, Michel $T$, McMurray JJV, Pfeffer MA, Solomon SD. Renin-Angiotensin-AIdosterone System Inhibitors in Patients with Covid-19. N Engl J Med. 2020 Apr 23;382(17):1653-1659. doi: 10.1056/NEJMsr2005760. Epub 2020 Mar 30. PMID: 32227760.

8. Kuster GM, Pfister O, Burkard T, Zhou Q, Twerenbold $R$, Haaf $P$, Widmer AF, Osswald S. SARS-CoV2: should inhibitors of the renin-angiotensin system be withdrawn in patients with COVID-19? Eur Heart J. 2020 May 14;41(19):1801-1803. doi: 10.1093/eurheartj/ ehaa235. PMID: 32196087.

9. Sommerstein R, Kochen MM, Messerli FH, Gräni C. Coronavirus Disease 2019 (COVID-19): Do Angiotensin-Converting Enzyme Inhibitors/Angiotensin Receptor Blockers Have a Biphasic Effect? J Am Heart Assoc. 2020 Apr 7;9(7):e016509. doi: 10.1161/JAHA.120.016509. Epub 2020 Apr 1. PMID: 32233753.

10. Ocaranza MP, Godoy I, Jalil JE, Varas M, Collantes P, Pinto M, Roman M, Ramirez C, Copaja M, Diaz-Araya G, Castro P, Lavandero S. Enalapril attenuates downregulation of Angiotensin-converting enzyme 2 in the late phase of ventricular dysfunction in myocardial infarcted rat. Hypertension. 2006 Oct;48(4):572-8. doi: 10.1161/01.HYP.0000237862.94083.45. Epub 2006 Aug 14. PMID: 16908757.

11. Epelman S, Shrestha K, Troughton RW, Francis GS, Sen S, Klein AL, Tang WH. Soluble angiotensin-converting enzyme 2 in human heart failure: relation with myocardial function and clinical outcomes. J Card Fail. 2009 Sep;15(7):565-71. doi: 10.1016/j. cardfail.2009.01.014. Epub 2009 Mar 17. PMID: 19700132.
12. Long B, Brady WJ, Koyfman A, Gottlieb M. Cardiovascular complications in COVID-19. Am J Emerg Med. 2020 Jul;38(7):1504-1507. doi: 10.1016/j. ajem.2020.04.048. Epub 2020 Apr 18. PMID: 32317203

13. Liang C, Zhang W, Li S, Qin G. Coronary heart disease and COVID-19: A meta-analysis. Med Clin (Barc). 2021 Jun 11;156(11):547-554. doi: 10.1016/j. medcli.2020.12.017. Epub 2021 Jan 28. PMID: 33632508.

14. Siripanthong B, Nazarian S, Muser D, Deo R, Santangeli P, Khanji MY, Cooper LT Jr, Chahal CAA. Recognizing COVID-19-related myocarditis: The possible pathophysiology and proposed guideline for diagnosis and management. Heart Rhythm. 2020 Sep;17(9):14631471. doi: 10.1016/j.hrthm.2020.05.001. Epub 2020 May 5. PMID: 32387246.

15. Agdamag ACC, Edmiston JB, Charpentier V, Chowdhury M, Fraser M, Maharaj VR, Francis GS, Alexy T. Update on COVID-19 Myocarditis. Medicina (Kaunas). 2020 Dec 9;56(12):678. doi: 10.3390/medicina56120678. PMID: 33317101.

16. Liu J, Deswal A, Khalid U. COVID-19 myocarditis and long-term heart failure sequelae. Curr Opin Cardiol. 2021 Mar 1;36(2):234-240. doi: 10.1097/ HCO.0000000000000832. PMID: 33394709.

17. Guzik TJ, Mohiddin SA, Dimarco A, Patel V, Savvatis $\mathrm{K}$, Marelli-Berg FM, Madhur MS, Tomaszewski M, Maffia P, D'Acquisto F, Nicklin SA, Marian AJ, Nosalski R, Murray EC, Guzik B, Berry C, Touyz RM, Kreutz R, Wang DW, Bhella D, Sagliocco O, Crea F, Thomson EC, McInnes IB. COVID-19 and the cardiovascular system: implications for risk assessment, diagnosis, and treatment options. Cardiovasc Res. 2020 Aug 1;116(10):1666-1687. doi: 10.1093/cvr/cvaa106. PMID: 32352535.

18. De Rosa S, Spaccarotella C, Basso C, Calabrò MP, Curcio A, Filardi PP, Mancone M, Mercuro G, Muscoli S, Nodari S, Pedrinelli R, Sinagra G, Indolfi C; Società Italiana di Cardiologia and the CCU Academy investigators group. Reduction of hospitalizations for myocardial infarction in Italy in the COVID-19 era. Eur Heart J. 2020 Jun 7;41(22):2083-2088. doi: 10.1093/ eurheartj/ehaa409. Erratum in: Eur Heart J. 2021 Feb 11;42(6):683. Erratum in: Eur Heart J. 2021 Jan 21;42(4):322. PMID: 32412631.

19. Solomon MD, McNulty EJ, Rana JS, Leong TK, Lee C, Sung SH, Ambrosy AP, Sidney S, Go AS. The Covid-19 Pandemic and the Incidence of Acute Myocardial Infarction. N Engl J Med. 2020 Aug 13;383(7):691-693. doi: 10.1056/NEJMc2015630. Epub 2020 May 19. PMID: 32427432.

20. Tedeschi D, Rizzi A, Biscaglia S, Tumscitz C. Acute myocardial infarction and large coronary thrombosis in a patient with COVID-19. Catheter Cardiovasc Interv. 2021 Feb 1;97(2):272-277. doi: 10.1002/ ccd.29179. Epub 2020 Aug 7. PMID: 32767631.

21. Ali A, Khattak MF, Khan MW. COVID-19 Pneumonia: ST-segment Elevation Myocardial Infarction (STEMI) and Myocarditis. Cureus. 2020 Dec 4;12(12):e11901. doi: 10.7759/cureus.11901. PMID: 33304708. 
22. Case BC, Yerasi C, Forrestal BJ, Shea C, Rappaport H, Medranda GA, Zhang C, Satler LF, Ben-Dor I, Hashim H, Rogers T, Waksman R. Comparison of Characteristics and Outcomes of Patients With Acute Myocardial Infarction With Versus Without Coronarvirus19. Am J Cardiol. 2021 Apr 1;144:8-12. doi: 10.1016/j. amjcard.2020.12.059. Epub 2020 Dec 29. PMID: 33385357.

23. Rodriguez-Leor $O$, Cid Alvarez AB, Pérez de Prado A, Rossello X, Ojeda S, Serrador A, López-Palop R, Martin-Moreiras J, Rumoroso JR, Cequier A, Ibáñez B, Cruz-González I, Romaguera R, Moreno R. In-hospital outcomes of COVID-19 ST-elevation myocardial infarction patients. Eurolntervention. $2021 \mathrm{Apr}$ 20;16(17):1426-1433. doi: 10.4244/EIJ-D-20-00935. PMID: 33164893.

24. Eroglu SE, Ademoglu E, Bayram S, Aksel G. A Rare Cause of ST-Segment Elevation Myocardial Infarction in COVID-19: MINOCA Syndrome. Medeni Med J. 2021;36(1):63-68. doi: 10.5222/MMJ.2021.25478. Epub 2021 Mar 26. PMID: 33828892.

25. Diaz-Arocutipa C, Torres-Valencia J, Saucedo-Chinchay J, Cuevas C. ST-segment elevation in patients with COVID-19: a systematic review. J Thromb Thrombolysis. 2021 Mar 1:1-8. doi: 10.1007/s11239021-02411-9. Epub ahead of print. PMID: 33646500.

26. Zhou F, Yu T, Du R, Fan G, Liu Y, Liu Z, Xiang J, Wang Y, Song B, Gu X, Guan L, Wei Y, Li H, Wu X, Xu J, Tu S, Zhang $Y$, Chen $\mathrm{H}, \mathrm{Cao} B$. Clinical course and risk factors for mortality of adult inpatients with COVID-19 in Wuhan, China: a retrospective cohort study. Lancet. 2020 Mar 28;395(10229):1054-1062. doi: 10.1016/ S0140-6736(20)30566-3. Epub 2020 Mar 11. Erratum in: Lancet. 2020 Mar 28;395(10229):1038. Erratum in: Lancet. 2020 Mar 28;395(10229):1038. PMID: 32171076.

27. Loffi M, Piccolo R, Regazzoni V, Di Tano G, Moschini L, Robba D, Quinzani F, Esposito G, Franzone A, Danzi GB. Coronary artery disease in patients hospitalised with Coronavirus disease 2019 (COVID-19) infection. Open Heart. 2020 Nov;7(2):e001428. doi: 10.1136/ openhrt-2020-001428. PMID: 33229434.

28. Nai Fovino L, Cademartiri F, Tarantini G. Subclinical coronary artery disease in COVID-19 patients. Eur Heart J Cardiovasc Imaging. 2020 Sep 1;21(9):10551056. doi: 10.1093/ehjci/jeaa202. PMID: 32671381.

29. Fried JA, Ramasubbu K, Bhatt R, Topkara VK, Clerkin KJ, Horn E, Rabbani L, Brodie D, Jain SS, Kirtane AJ, Masoumi A, Takeda K, Kumaraiah D, Burkhoff D, Leon M, Schwartz A, Uriel N, Sayer G. The Variety of Cardiovascular Presentations of COVID-19. Circulation. 2020 Jun 9;141(23):1930-1936. doi: 10.1161/ CIRCULATIONAHA.120.047164. Epub 2020 Apr 3. PMID: 32243205.

30. Chen T, Wu D, Chen H, Yan W, Yang D, Chen G, Ma K, Xu D, Yu H, Wang H, Wang T, Guo W, Chen J, Ding C, Zhang $X$, Huang J, Han M, Li S, Luo X, Zhao J, Ning Q. Clinical characteristics of 113 deceased patients with coronavirus disease 2019: retrospective study. BMJ. 2020 Mar 26;368:m1091. doi: 10.1136/bmj. m1091. Erratum in: BMJ. 2020 Mar 31;368:m1295. PMID: 32217556.
31. Rey JR, Caro-Codón J, Rosillo SO, Iniesta ÁM, Castrejón-Castrejón S, Marco-Clement I, Martín-Polo L, Merino-Argos C, Rodríguez-Sotelo L, García-Veas JM, Martínez-Marín LA, Martínez-Cossiani M, Buño A, Gonzalez-Valle L, Herrero A, López-Sendón JL, Merino JL; CARD-COVID Investigators. Heart failure in COVID-19 patients: prevalence, incidence and prognostic implications. Eur J Heart Fail. 2020 Dec;22(12):2205-2215. doi: 10.1002/ejhf.1990. Epub 2020 Oct 7. PMID: 32833283.

32. Babapoor-Farrokhran S, Rasekhi RT, Gill D, Babapoor S, Amanullah A. Arrhythmia in COVID-19. SN Compr Clin Med. 2020 Aug 14:1-6. doi: 10.1007/s42399-02000454-2. Epub ahead of print. PMID: 32838188.

33. Peigh G, Leya MV, Baman JR, Cantey EP, Knight BP, Flaherty JD. Novel coronavirus 19 (COVID-19) associated sinus node dysfunction: a case series. Eur Heart J Case Rep. 2020 May 8;4(FI1):1-6. doi: 10.1093/ ehjcr/ytaa132. PMID: 33089039.

34. Hu YF, Cheng WH, Hung Y, Lin WY, Chao TF, Liao JN, Lin YJ, Lin WS, Chen YJ, Chen SA. Management of Atrial Fibrillation in COVID-19 Pandemic. Circ J. 2020 Sep 25;84(10):1679-1685. doi: 10.1253/circj.CJ-200566. Epub 2020 Sep 9. PMID: 32908073.

35. Wu Cl, Postema PG, Arbelo E, Behr ER, Bezzina CR, Napolitano C, Robyns T, Probst V, Schulze-Bahr E, Remme CA, Wilde AAM. SARS-CoV-2, COVID-19, and inherited arrhythmia syndromes. Heart Rhythm. 2020 Sep;17(9):1456-1462. doi: 10.1016/j. hrthm.2020.03.024. Epub 2020 Mar 31. PMID: 32244059 .

36. Alonso-Fernández A, Toledo-Pons N, Cosío BG, Millán $A$, Calvo N, Ramón L, de Mendoza SH, MoreII-García D, Bauça-Rossello JM, Núñez B, Pons J, Palmer JA, Martín L, Peñaranda M, Pou JA, Sauleda J, Sala-Llinas E. Prevalence of pulmonary embolism in patients with COVID-19 pneumonia and high D-dimer values: A prospective study. PLoS One. 2020 Aug 25;15(8):e0238216. doi: 10.1371/journal. pone.0238216. PMID: 32841275.

37. Tang N, Li D, Wang X, Sun Z. Abnormal coagulation parameters are associated with poor prognosis in patients with novel coronavirus pneumonia. J Thromb Haemost. 2020 Apr;18(4):844-847. doi: 10.1111/jth.14768. Epub 2020 Mar 13. PMID: 32073213

38. Tang N, Bai H, Chen X, Gong J, Li D, Sun Z. Anticoagulant treatment is associated with decreased mortality in severe coronavirus disease 2019 patients with coagulopathy. J Thromb Haemost. 2020 May;18(5):1094-1099. doi: 10.1111/jth.14817. Epub 2020 Apr 27. PMID: 32220112.

39. Bompard F, Monnier H, Saab I, Tordjman M, Abdoul H, Fournier L, Sanchez O, Lorut C, Chassagnon G, Revel MP. Pulmonary embolism in patients with COVID-19 pneumonia. Eur Respir J. 2020 Jul 30;56(1):2001365. doi: 10.1183/13993003.01365-2020. PMID: 32398297.

40. Klok FA, Kruip MJHA, van der Meer NJM, Arbous MS, Gommers DAMPJ, Kant KM, Kaptein FHJ, van Paassen J, Stals MAM, Huisman MV, Endeman H. Incidence of thrombotic complications in critically ill ICU patients with COVID-19. Thromb Res. 2020 
Jul;191:145-147. doi: 10.1016/j.thromres.2020.04.013. Epub 2020 Apr 10. PMID: 32291094.

41. Singh N, Anchan RK, Besser SA, Belkin MN, Cruz MD, Lee L, Yu D, Mehta N, Nguyen AB, Alenghat FJ. High sensitivity Troponin-T for prediction of adverse events in patients with COVID-19. Biomarkers. 2020 Dec;25(8):626-633. doi: 10.1080/1354750X.2020.1829056. Epub 2020 Nov 24. PMID: 32981387.

42. Yancy CW, Jessup M, Bozkurt B, Butler J, Casey DE Jr, Colvin MM, Drazner MH, Filippatos GS, Fonarow GC, Givertz MM, Hollenberg SM, Lindenfeld J, Masoudi FA, McBride PE, Peterson PN, Stevenson LW, Westlake C. 2017 ACC/AHA/HFSA Focused Update of the 2013 ACCF/AHA Guideline for the Management of Heart Failure: A Report of the American College of Cardiology/American Heart Association Task Force on Clinical Practice Guidelines and the Heart Failure Society of America. J Am Coll Cardiol. 2017 Aug 8;70(6):776-803. doi: 10.1016/j.jacc.2017.04.025. Epub 2017 Apr 28. PMID: 28461007.

43. Gohar A, Chong JPC, Liew OW, den Ruijter H, de Kleijn DPV, Sim D, Yeo DPS, Ong HY, Jaufeerally F, Leong GKT, Ling LH, Lam CSP, Richards AM. The prognostic value of highly sensitive cardiac troponin assays for adverse events in men and women with stable heart failure and a preserved vs. reduced ejection fraction. Eur J Heart Fail. 2017 Dec;19(12):16381647. doi: 10.1002/ejhf.911. Epub 2017 Aug 28. PMID: 28849609.

44. Shi S, Qin M, Shen B, Cai Y, Liu T, Yang F, Gong W, Liu X, Liang J, Zhao Q, Huang $\mathrm{H}$, Yang B, Huang C. Association of Cardiac Injury With Mortality in Hospitalized Patients With COVID-19 in Wuhan, China. JAMA Cardiol. 2020 Jul 1;5(7):802-810. doi: 10.1001/ jamacardio.2020.0950. PMID: 32211816.

45. Aikawa T, Takagi H, Ishikawa K, Kuno T. Myocardial injury characterized by elevated cardiac troponin and in-hospital mortality of COVID-19: An insight from a meta-analysis. J Med Virol. 2021 Jan;93(1):51-55. doi: 10.1002/jmv.26108. Epub 2020 Jun 19. PMID: 32484975.

46. Salvatici M, Barbieri B, Cioffi SMG, Morenghi E, Leone FP, Maura F, Moriello G, Sandri MT. Association between cardiac troponin I and mortality in patients with COVID-19. Biomarkers. 2020 Dec;25(8):634640. doi: 10.1080/1354750X.2020.1831609. Epub 2020 Nov 24. PMID: 33003961.

47. Yang J, Liao X, Yin W, Wang B, Yue J, Bai L, Liu D, Zhu T, Huang Z, Kang Y; Study of 2019 Novel Coronavirus Pneumonia Infected Critically III Patients in Sichuan Province (SUNRISE) Group. Elevated cardiac biomarkers may be effective prognostic predictors for patients with COVID-19: A multicenter, observational study. Am J Emerg Med. 2021 Jan;39:34-41. doi: 10.1016/j.ajem.2020.10.013. Epub 2020 Oct 13. PMID: PMC7553004.

48. Yu Y, Xu D, Fu S, Zhang J, Yang X, Xu L, Xu J, Wu Y, Huang $C$, Ouyang $Y$, Yang $L$, Fang $M, X i a o H, M a ~ J$, Zhu W, Hu S, Hu Q, Ding D, Hu M, Zhu G, Xu W, Guo J, Xu J, Yuan H, Zhang B, Yu Z, Chen D, Yuan S, Shang Y. Patients with COVID-19 in 19 ICUs in Wuhan, Chi- na: a cross-sectional study. Crit Care. 2020 May 14;24(1):219. doi: 10.1186/s13054-020-02939-x. PMID: 32410714.

49. Gao L, Jiang D, Wen XS, Cheng XC, Sun M, He B, You LN, Lei P, Tan XW, Qin S, Cai GQ, Zhang DY. Prognostic value of NT-proBNP in patients with severe COVID-19. Respir Res. 2020 Apr 15;21(1):83. doi: 10.1186/ s12931-020-01352-w. PMID: 32293449.

50. Jeong KY, Kim K, Kim TY, Lee CC, Jo SO, Rhee JE, Jo $\mathrm{YH}$, Suh GJ, Singer AJ. Prognostic value of $\mathrm{N}$-terminal pro-brain natriuretic peptide in hospitalised patients with community-acquired pneumonia. Emerg Med J. 2011 Feb;28(2):122-7. doi: 10.1136/emj.2009.089383. Epub 2010 May 29. PMID: 20511643.

51. Henry BM, Aggarwal G, Wong J, Benoit S, Vikse J, Plebani M, Lippi $G$. Lactate dehydrogenase levels predict coronavirus disease 2019 (COVID-19) severity and mortality: A pooled analysis. Am J Emerg Med. 2020 Sep;38(9):1722-1726. doi: 10.1016/j.ajem.2020.05.073. Epub 2020 May 27. PMID: 32738466.

52. Szarpak L, Ruetzler K, Safiejko K, Hampel M, Pruc $M$, Kanczuga-Koda L, Filipiak KJ, Jaguszewski MJ. Lactate dehydrogenase level as a COVID-19 severity marker. Am J Emerg Med. 2021 Jul;45:638-639. doi: 10.1016/j.ajem.2020.11.025. Epub 2020 Nov 15. PMID: 33246860.

53. Szarpak $Ł$, Nowak B, Kosior D, Zaczynski A, Filipiak KJ, Jaguszewski MJ. Cytokines as predictors of COVID-19 severity: evidence from a meta-analysis. Pol Arch Intern Med. 2021 Jan 29;131(1):98-99. doi: 10.20452/pamw.15685. Epub 2020 Nov 21. PMID: 33219785.

54. Ruetzler K, Szarpak Ł, Ładny JR, Gąsecka A, Gilis-Malinowska N, Pruc M, Smereka J, Nowak B, Filipiak $\mathrm{KJ}$, Jaguszewski MJ. D-dimer levels predict COVID-19 severity and mortality. Kardiol Pol. 2021 Feb 25;79(2):217-218. doi: 10.33963/KP.15830. Epub 2021 Feb 25. PMID: 33635034.

55. Bergamaschi L, D'Angelo EC, Paolisso P, Toniolo $S$, Fabrizio M, Angeli F, Donati F, Magnani I, Rinaldi A, Bartoli L, Chiti C, Biffi M, Pizzi C, Viale P, Galié $N$. The value of ECG changes in risk stratification of COVID-19 patients. Ann Noninvasive Electrocardiol. 2021 May;26(3):e12815. doi: 10.1111/anec.12815. Epub 2021 Jan 29. PMID: 33512742.

56. Angeli F, Spanevello A, De Ponti R, Visca D, Marazzato J, Palmiotto G, Feci D, Reboldi G, Fabbri LM, Verdecchia P. Electrocardiographic features of patients with COVID-19 pneumonia. Eur J Intern Med. 2020 Aug;78:101-106. doi: 10.1016/j.ejim.2020.06.015. Epub 2020 Jun 20. PMID: 32586646.

57. Cresti A, Barchitta A, Barbieri A, Monte IP, Trocino G, Ciampi $Q$, Miceli S, Petrella L, Jaric E, Solari M, Basso C, Pepi M, Antonini-Canterin F. Echocardiography and Multimodality Cardiac Imaging in COVID19 Patients. J Cardiovasc Echogr. 2020 Oct;30(Suppl 2):S18-S24. doi: 10.4103/jcecho.jcecho_58_20. Epub 2020 Oct 27. PMID: 33489732.

58. Szymański P, Gackowski A, Mizia-Stec K, Kasprzak JD, Lipczyńska M, Lipiec P, Trojnarska O, Wejner-Mik $P$, Sorysz D, Sobkowicz B, Oko-Sarnowska Z, Wysokiński A, Szyszka A, Płońska-Gościniak 
E, Gąsior Z, Ciurzyński M, Pasierski T, Hoffman P. Echocardiography during the coronavirus disease 2019 pandemic - the impact of the vaccination program. A 2021 update of the expert opinion of the Working Group on Echocardiography of the Polish Cardiac Society. Kardiol Pol. 2021;79(5):595-603. doi: 10.33963/KP.15973. PMID: 34125943.

59. Dweck MR, Bularga A, Hahn RT, Bing R, Lee KK, Chapman AR, White A, Salvo GD, Sade LE, Pearce K, Newby DE, Popescu BA, Donal E, Cosyns B, Edvardsen T, Mills NL, Haugaa K. Global evaluation of echocardiography in patients with COVID-19. Eur Heart J Cardiovasc Imaging. 2020 Sep 1;21(9):949-958. doi: 10.1093/ehjci/jeaa178. PMID: 32556199.

60. Churchill TW, Bertrand PB, Bernard S, Namasivayam M, Churchill J, Crousillat D, Davis EF, Hung J, Picard $\mathrm{MH}$. Echocardiographic Features of COVID-19 IIIness and Association with Cardiac Biomarkers. J Am Soc Echocardiogr. 2020 Aug;33(8):1053-1054. doi: 10.1016/j.echo.2020.05.028. Epub 2020 May 28. PMID: 32580898.

61. Li Y, Li H, Zhu S, Xie Y, Wang B, He L, Zhang D, Zhang Y, Yuan H, Wu C, Sun W, Zhang Y, Li M, Cui L, Cai Y, Wang J, Yang Y, Lv Q, Zhang L, Xie M. Prognostic Value of Right Ventricular Longitudinal Strain in Patients With COVID19. JACC Cardiovasc Imaging. 2020 Nov;13(11):22872299. doi: 10.1016/j.jcmg.2020.04.014. Epub 2020 Apr 28. PMID: 32654963.
62. Ojha V, Verma M, Pandey NN, Mani A, Malhi AS, Kumar $S$, Jagia P, Roy A, Sharma S. Cardiac Magnetic Resonance Imaging in Coronavirus Disease 2019 (COVID19): A Systematic Review of Cardiac Magnetic Resonance Imaging Findings in 199 Patients. J Thorac Imaging. 2021 Mar 1;36(2):73-83. doi: 10.1097/ RTI.0000000000000574. PMID: 33306666.

63. Esposito A, Palmisano A, Natale L, Ligabue G, Peretto G, Lovato L, Vignale D, Fiocchi F, Marano R, Russo V. Cardiac Magnetic Resonance Characterization of Myocarditis-Like Acute Cardiac Syndrome in COVID19. JACC Cardiovasc Imaging. 2020 Nov;13(11):24622465. doi: 10.1016/j.jcmg.2020.06.003. Epub 2020 Jun 24. PMID: 32654966.

64. Pontone G, Scafuri S, Mancini ME, Agalbato C, Guglielmo M, Baggiano A, Muscogiuri G, Fusini L, Andreini $D$, Mushtaq S, Conte E, Annoni A, Formenti A, Gennari AG, Guaricci Al, Rabbat MR, Pompilio G, Pepi M, Rossi A. Role of computed tomography in COVID-19. J Cardiovasc Comput Tomogr. 2021 Jan-Feb;15(1):2736. doi: 10.1016/j.jcct.2020.08.013. Epub 2020 Sep 4. PMID: 32952101.

65. Axsom K, Lin F, Weinsaft JW, Min JK. Evaluation of myocarditis with delayed-enhancement computed tomography. J Cardiovasc Comput Tomogr. 2009 Nov-Dec;3(6):409-11. doi: 10.1016/j.jcct.2009.09.003. Epub 2009 Sep 24. PMID: 20083062. 